\title{
25-Hydroxycholecalciferol
}

\section{A COMPARATIVE STUDY IN DEFICIENCY RICKETS AND DIFFERENT TYPES OF RESISTANT RICKETS}

\author{
Sonta Balsan and Michele Garabedian \\ From the Unité de Recherches sur les Maladies du Métabolisme de \\ l'Enfant, Hopital des Enfants Malades, 149, rue de Sèvres, \\ 75-Paris XVe, France
}

A B S T R A C T The effects of 25 -hydroxycholecalciferol
were studied in 4 children with deficiency rickets and
22 children with D-resistant rickets, including patients
with hereditary hypophosphatemic D-resistant rickets,
"pseudo-deficiency" rickets, and rickets secondary to
cystinosis or to tyrosinosis. Three protocols were used.
(a) 8 days after a single oral dose of 16,000 IU of
25-hydroxycholecalciferol, normalization of all biological
parameters was observed in all cases of deficiency
rickets. A complete lack of response was observed in
the different types of resistant rickets. (b) Under pro-
longed administration of 2,640 IU/day for 2 months,
clinical-biological symptoms and X-ray lesions disap-
peared, and a catch-up growth pattern was observed
in deficiency rickets; no relapse of rickets occurred up
to 5 months after therapy was stopped. The same dose
had no significant effect in 10 patients with hereditary
hypophosphatemic D-resistant rickets. A bone biopsy
performed in one case showed the persistence of charac-
teristic lesions. (c) With increasing doses of 25 -hy-
droxycholecalciferol varying from 6,000 to 30,000 IU/
day and a follow-up of 6 months up to 2 yr duration,
clinical-biological-radiologic recovery and catch-up
growth was obtained in all cases of "pseudo-deficiency"
rickets. In hypophosphatemic hereditary D-resistant
rickets, 5 out of 13 patients' serum concentration of
phosphorus reached at least 30 mg/liter, but a catch-up
growth pattern was not observed. These results indi-
cate that (a) 25 -hydroxycholecalciferol is highly active

A preliminary report was given at the Franklin McLean Commemorative Conference on Cell Mechanisms for Calcium Transfer and Homeostasis, Portsmouth, New Hampshire, September, 1970.

Dr. Balsan is Maitre de Recherches au Centre National de la Recherche Scientifique.

Received for publication 25 March 1971 and in revised form 27 September 1971. in deficiency rickets; $(b)$ a defect in the conversion of vitamin $D_{3}$ to its active 25 -hydroxy metabolite is probably not the metabolic defect in any of the different types of vitamin D-resistant rickets studied.

\section{INTRODUCTION}

DeLuca and his colleagues have introduced a new field of investigation by the discovery of the active metabolites of vitamin $\mathrm{D}_{3}(1-5)$. The activity and the metabolism of these metabolites are known mainly by experimental studies on laboratory animals, in tissue cultures, and on isolated organs (6-16). Preliminary results on the biological effects (17) and on the therapeutic effects of 25-hydroxycholecalciferol $(25-\mathrm{HCC})^{1}$ in man have been reported (18-21). Furthermore, DeLuca, Lund, Rosenbloom, and Lobeck (22) ; Avioli, Williams, Lund, and DeLuca (24); and Avioli, Birge, Lee, and Slatopolsky (23) have demonstrated abnormalities in vitamin $\mathrm{D}_{3}$ metabolism in hereditary vitamin D-resistant rickets and in chronic renal failure. Thus, the possibility that resistance to vitamin $\mathrm{D}$ might be explained by a defect in the conversion of the vitamin to its 25-hydroxylated metabolites was suggested. Recently, Earp, Ney, Gitelman, Richman, and DeLuca (25) reported the responses of five patients with hereditary hypophosphatemic rickets to short-term administration of small doses of $25-\mathrm{HCC}$, and they concluded that such a defect (in formation of 25-HCC) appears not to be solely responsible for the metabolic abnormalities seen in this disease.

The purpose of our study was to investigate further this possibility by comparing the effects of $25-\mathrm{HCC}$ in

${ }^{1}$ Abbreviations used in this paper: 25-HCC, 25-hydroxycholecalciferol; TRP, tubular reabsorption of phosphorus; VDRR, hypophosphatemic vitamin D-resistant rickets. 
deficiency rickets and in different types of D-resistant rickets: hereditary hypophosphatemic D-resistant resistant rickets (VDRR), "pseudo-deficiency" rickets, and resistant rickets secondary to cystinosis or tyrosinosis.

Our data demonstrate: (a) that 25-HCC has antirachitic activity in man; (b) that these patients with different types of D-resistant rickets are also resistant to $25-\mathrm{HCC}$; and $(c)$ that in the group of patients with hereditary hypophosphatemic D-resistant rickets, sensitivity to high doses of $25-\mathrm{HCC}$ varies greatly from one subject to another whereas all children with "pseudodeficiency" rickets are highly responsive to increasing doses of $25-\mathrm{HCC}$.

\section{METHODS}

Subjects. The subjects studied included 4 children with deficiency rickets, 4 patients with "pseudo-deficiency" rickets as described by Prader, Illig, and Heierli (26), 13 with hereditary hypophosphatemic D-resistant rickets, and 5 children with secondary resistant rickets. In this last group four patients had cystinosis and one had tyrosinosis. None of the four children, aged 13-38 months, with deficiency rickets had ever been treated with vitamin D. All patients with idiopathic or secondary rickets had been previously treated with vitamin $D_{8}$. Daily doses of vitamin $D_{3}$ varied from 3,000 IU/day to $80,000 \mathrm{IU} /$ day. Vitamin $\mathrm{D}$ treatment had been stopped for 1 wk to 5 months when the first protocol of the present study was started.

25-HCC. The 25-HCC (Roussel H 4682, Roussel Laboratories, Paris, France) was synthesized according to the Blunt and DeLuca technique (27). Each ampoule contained $0.133 \mathrm{mg}$ of crystalline $25-\mathrm{HCC}$, dissolved in 0.125 $\mathrm{ml}$ of ethyl alcohol and arachis oil to a total volume of $2.5 \mathrm{ml}$. The biologic activity of the $25-\mathrm{HCC}$ was checked on vitamin $\mathrm{D}$-deficient rats according to the technique of Blunt, Tanaka, and DeLuca (7). One ampoule of 25-HCC corresponded to 7,980 IU. $25-\mathrm{HCC}$ was given orally to patients just before breakfast.

Protocols. The effects of $25-\mathrm{HCC}$ were studied by collecting the following data: (a) serum calcium, magnesium, inorganic phosphorous, citrate, alkaline phosphatase, and creatinine; (b) urine calcium, phosphorous, magnesium, citrate, and creatinine; (c) endogenous creatinine clearance and tubular reabsorption of phosphorous (TRP); (d) X-ray changes. Three protocols were utilized in the collection of data: (a) 4 days before and 8 days after the administration of a single oral dose of $0.266 \mathrm{mg}$ or 16,000 IU of 25-HCC; (b) during administration of $0.044 \mathrm{mg}$ or 2,640 IU/day for 2 months, and 2-12 months after 25HCC was stopped; and (c) during the administration of increasing doses of 25-HCC. In the latter instances doses were increased from 6,000 to $30,000 \mathrm{IU} /$ day if hypophosphatemia and/or hypocalcemia persisted.

Short-term balance studies on three children with VDRR under protocol A were carried out.

Protocol B was completed in one case of VDRR with histologic and microradiographic studies made on a bone biopsy. The child was given $1.5 \mathrm{~g}$ of tetracycline the first and last day of 25-HCC administration. The bone biopsy was taken surgically at the metaphyseal end of the peroneus during corrective osteotomy for severe genu valgum. A growth curve was prepared in every case where protocol C was followed.
The laboratory techniques used were the following: creatinine, Jaffé's reaction (autoanalyzer); phosphorous, Fiske and SubbaRow's technique (autoanalyzer); calcium, complexometric titration with plasma Corinth B (E. Guzz Corp., London, England) (28) ; magnesium, Atomic Absorption (Perkin-Elmer Corp., Norwalk, Conn.) ; alkaline phosphatase, Bodansky method; and citrates, colorimetric technique (29). The histologic and microradiographic methods used have been described in detail previously (30).

Results in cases of resistance to vitamin D were compared: (a) with observations made in deficiency rickets; and $(b)$ with results obtained previously under vitamin $D_{a}$ therapy.

Student's $t$ test and Wilcoxon W test were used for statistical analysis of results (31).

\section{RESULTS}

\section{Single oral dose of 25-HCC: $0.266 \mathrm{mg}$ or $16,000 \mathrm{IU}$ (protocol A)}

21 children were studied with protocol A. All studies were made in a metabolic unit, the diet being strictly controlled. The following results were observed.

Deficiency rickets $(n=3)$. Normalization of serum calcium in two cases, of serum phosphorous and alkaline phosphatase, and increase of serum citrate concentration in all three cases was observed (Fig. 1). The effect of $25-\mathrm{HCC}$ on serum calcium concentration was most striking in one patient whose prior serum calcium was low, 74 and $81 \mathrm{mg} / \mathrm{liter}$. It increased to $99 \mathrm{mg} /$ liter 8 days after $16,000 \mathrm{IU}$ of 25 -HCC. In all three patients $25-\mathrm{HCC}$ was very effective on serum phosphorous concentration. The increase of serum phosphorous is highly significant the 3 rd $(P<0.01)$ and the 8th $(P<0.001)$ day after 25-HCC. Serum phosphorus concentration expressed as mean \pm one standard deviation increased from $40.67 \pm 11.69 \mathrm{mg} /$ liter during the control period to $43.66 \pm 10.02 \mathrm{mg} / \mathrm{liter}$ one day after $25-\mathrm{HCC}$, to $51 \pm 11.27 \mathrm{mg} / \mathrm{liter}$ the $3 \mathrm{rd}$ day and $60 \pm 12.10$ the 8 th day after $25-$ HCC. Mean serum citrate was $22.86 \pm 3.55 \mathrm{mg} /$ liter during the control period and increased to $30.83 \pm 1.53 \mathrm{mg} /$ liter $(P<0.05) 8$ days after the single oral dose of $25-\mathrm{HCC}$. No significant effect of $25-\mathrm{HCC}$ on serum magnesium concentration, creatinine clearance, TRP, calciuria, diuresis, magnesiuria, or citraturia was observed.

Hereditary hypophosphatemic D-resistant rickets (n $=10)$, "pseudo-deficiency" rickets $(n=3)$, secondary resistant rickets $(n=5)$. A single dose of 16,000 IU of 25-HCC had no effect on serum calcium, phosphorous, or alkaline phosphatase in the different types of resistant rickets studied. Fig. 2 illustrates the results observed in cases of VDRR. None of the other biological parameters studied showed any significant change after 25-HCC.

In three cases of VDRR, short-term balance studies were performed during three periods, each period being 


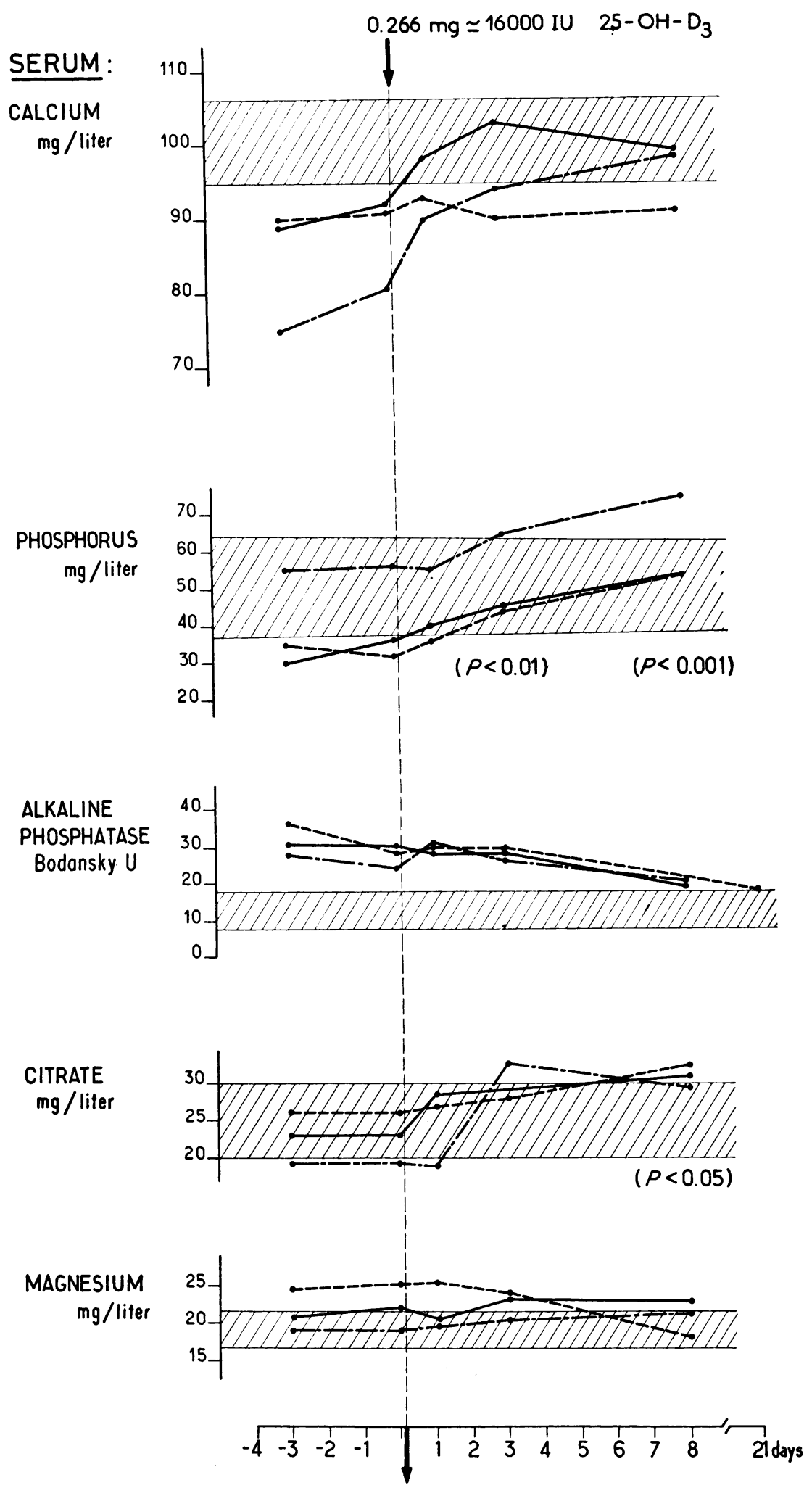

Figure 1 Deficiency rickets. Effects of a single dose of 25-HCC. Each line represents the results with one patient. 


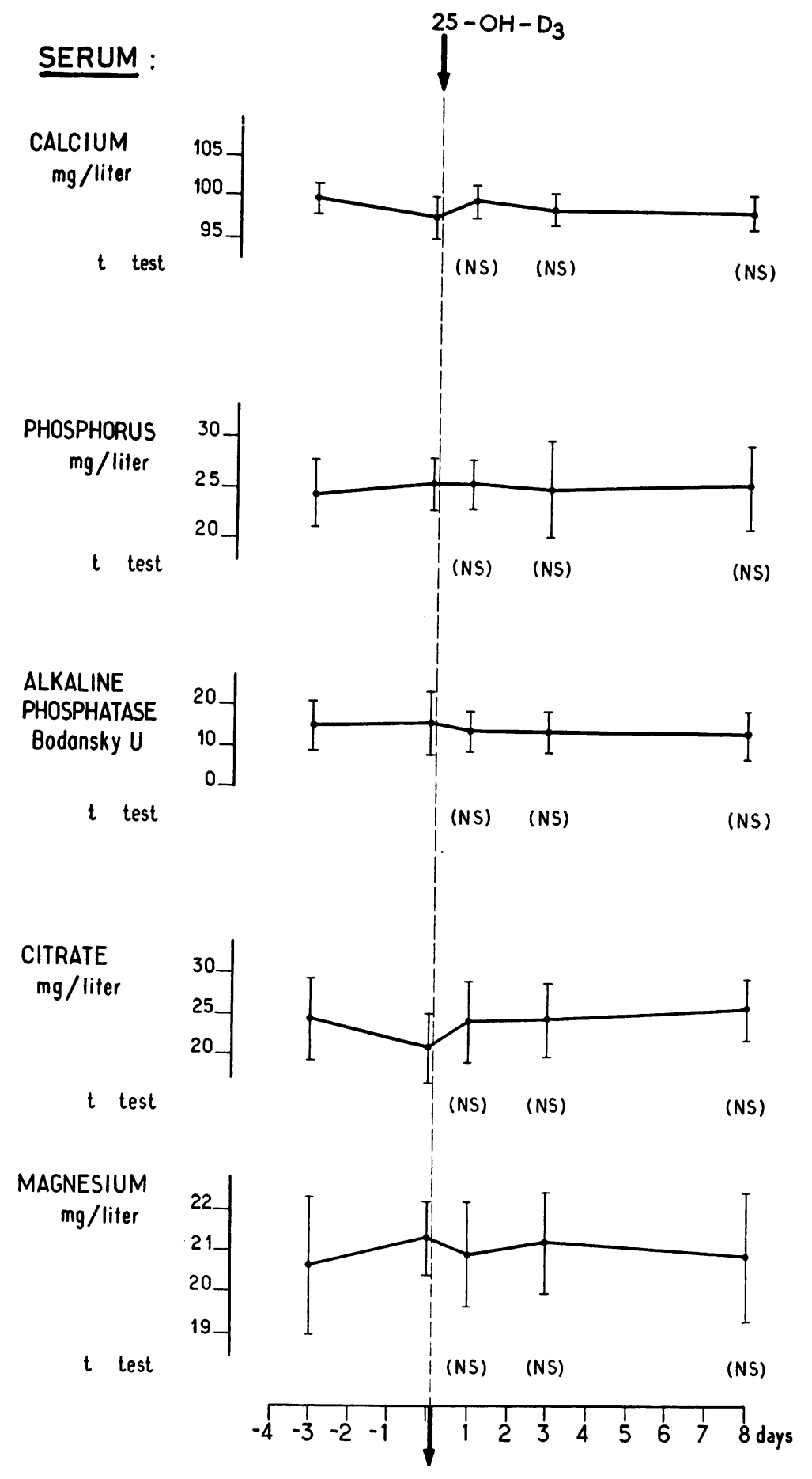

FIGURE 2 Hereditary vitamin D-resistant rickets (VDRR). $(n=10)$. Effects of a single dose of 25-hydroxycholecalciferol $\left(25-\mathrm{OH}-\mathrm{D}_{3}\right): 0.266$ mg or $16,000 \mathrm{IU}$. Mean \pm SD values (vertical bars) are shown.

of 5 days, one control period before 25-HCC and two consecutive periods immediately after the administration of 25-HCC. No significant change in calcium or phosphorous balances was observed.
Administration of $0.044 \mathrm{mg}$ or $2,600 \mathrm{IU} /$ day per 2 months of 25-HCC (Protocol B)

4 children with deficiency rickets and 10 patients with VDRR were studied with the protocol $B$.

\section{S. Balsan and M. Garabedian}


Deficiency rickets. Due to a severe hypocalcemia at admission at the hospital, i.e. $59 \mathrm{mg} /$ liter, protocol $\mathrm{B}$ was started with one patient after $18 \mathrm{hr}$ of a calcium infusion. The infusion was continued 8 days with decreasing doses of calcium, then stopped and replaced by oral supplementation of calcium. The clinical course and radiologic changes in these four cases were as follows: an improvement of clinical symptoms appeared shortly after the beginning of 25-HCC therapy, hypotonia disappeared in $2 \mathrm{wk}$, and a gain of appetite was noted in the same period. One patient had a severe respiratory syndrome with polypnea and dyspnea. These symptoms diminished in intensity then disappeared 1 month after the beginning of treatment. All four children had significant growth retardation before treatment. Catch-up growth was observed in these patients during 25-HCC treatment and after 25-HCC treatment was stopped (Fig. 3). Laboratory studies showed persistently normal values for serum calcium, serum phosphorous, and alkaline phosphatase concentrations after 25-HCC treatment, From 5 to 9 months after the end of 25-HCC administration, no clinical, biological, or radiologic relapse was observed in two cases (Fig. 4). However, two children had slight biological relapses with a decrease in serum phosphorous concentration and an increase in serum alkaline phosphatase 5 months after $25-\mathrm{HCC}$ was stopped. Treatment with very small doses of $25-\mathrm{HCC}$, i.e. 400 IU per day, was sufficient to promote normalization of all parameters in 8 days in both children (Fig. 5).

The effects of 25-HCC on bone as revealed by X-ray examination in deficiency rickets were evident after the 3rd wk of therapy. Healing of metaphyseal lesions was complete at the end of $8 \mathrm{wk}$ of $25-\mathrm{HCC}$ ingestion.

$V D R R$. In contrast to the striking clinical, biological, and radiologic healing promoted by $25-\mathrm{HCC}$ in deficiency rickets no improvement in VDRR patients, especially of the abnormally low serum phosphorous concentration (Fig. 6), was noted after treatment with $25-\mathrm{HCC}$ at the dose of 2,600 IU/day for 2 months.

In one child, the bone was labeled with tetracycline before and after 25-HCC treatment, and the bone biopsy was studied (Dr. Giulia Witmer) in serial sections. In the tissue during 25-HCC therapy, there were large osteoid steams and perilacunar lesions characteristic of the disease (Fig. 7 ).

\section{Long-term study with increasing doses of 25-HCC (Protocol C)}

This protocol with daily doses of $25-\mathrm{HCC}$ varying from 6,000 to 30,000 IU was used in 13 cases of VDRR and 4 patients with "pseudo-deficiency" rickets.
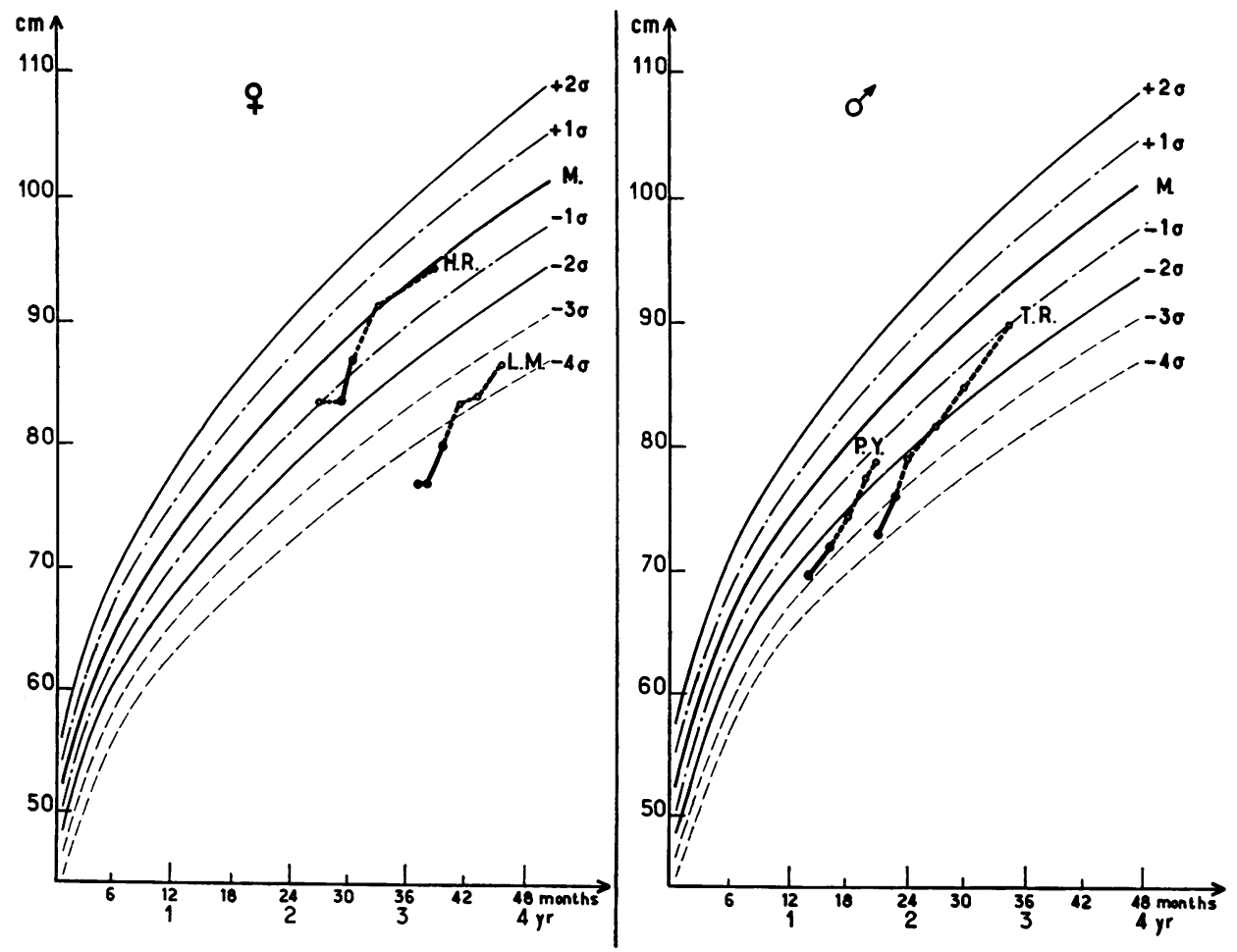

Figure 3 Growth curves in four cases of deficiency rickets. Straight lines: on 25-HCC therapy; dotted lines: after $25-\mathrm{HCC}$ treatment was stopped. 


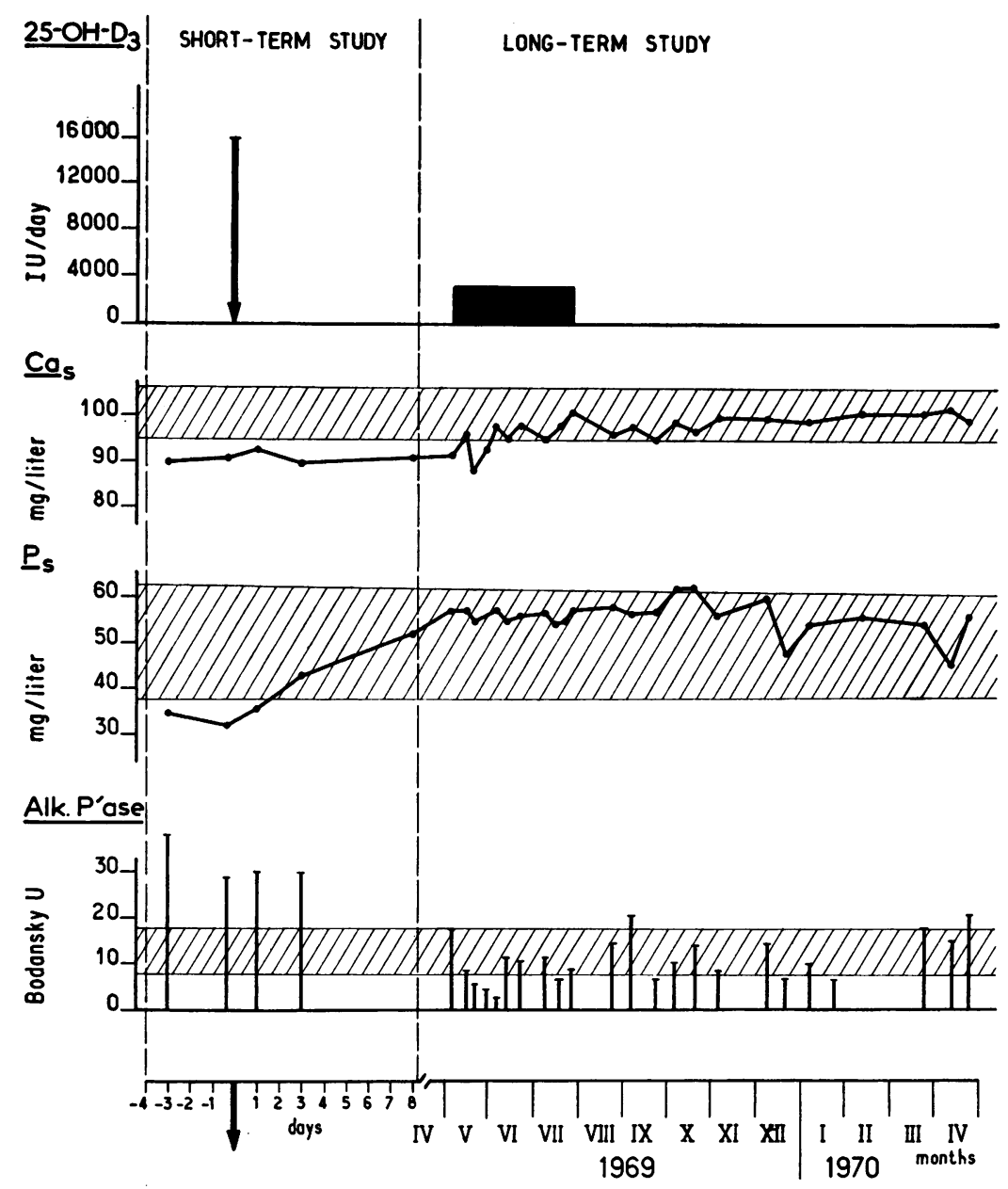

FIGURE 4 Effect of prolonged administration (2 months) of 2,640 IU/day of $25-\mathrm{HCC}\left(25-\mathrm{OH}-\mathrm{D}_{3}\right)$ in one patient (L. M. $\left.9-24-\mathrm{II}-1966\right)$ with deficiency rickets. Note that no relapse occurred as long as 9 months after the end of 25-HCC therapy.

$V D R R$. In VDRR serum phosphorus concentration reached at least $30 \mathrm{mg} / \mathrm{liter}$ in 5 out of 13 patients (Table I). Sensitivity to $25-\mathrm{HCC}$ was variable, however. In four cases (observations I, II, III, and IV) $6,000 \mathrm{IU} /$ day were sufficient, while in another case (observation V), 12,000 IU/day was required. In the remaining eight cases 18,000 to $30,000 \mathrm{IU} /$ day failed to produce a response. No hypercalcemia was observed during this investigation. The only side effect noted was a significant increase of urinary calcium excretion in four patients. Urinary calcium excretion reached 8 to 10 $\mathrm{mg} / \mathrm{kg}$ per $24 \mathrm{hr}^{2}{ }^{2}$

Hypercalcuria was easily controlled by the use of oral phosphate supplementation $(0.75 \mathrm{~g} /$ day of phosphorous in children under $10 \mathrm{yr}$ of age and $1 \mathrm{~g} /$ day in those older).

\footnotetext{
${ }^{2}$ Normal values in our laboratory; mean $3.2 \mathrm{mg} / \mathrm{per} 24$ hr. Lower limit $0.3 \mathrm{mg} / \mathrm{kg}$ per $24 \mathrm{hr}$, upper limit $8 \mathrm{mg} / \mathrm{kg}$ per $24 \mathrm{hr}$ for the $95 \%$ probability.
}

"Pseudo-deficiency rickets" $(n=4)$. In all four cases it was possible to obtain normalization of serum calcium and serum phosphorous concentrations (Fig. 8) with increasing doses of 25-HCC. The two younger children with very severe skeletal lesions required higher doses, i.e. 12,000-24,000 IU/day (Fig. 8). Healing of these lesions was obtained after 8 months of treatment.

Catch-up growth was observed in the two children presenting very significant growth retardation at the start of $25-\mathrm{HCC}$ therapy. On the 8th month of treatment, they had gained respectively 11 and $10.5 \mathrm{~cm}$ in height and 3 and $3.1 \mathrm{~kg}$ in weight.

By comparing the biological effects of various doses of 25-HCC, and the effects of the previous vitamin D treatment, in VDRR and "pseudo-deficiency" rickets we have the impression that $25-\mathrm{HCC}$ is 5 to 8 times more active than vitamin $D_{3}$ on a weight basis. 

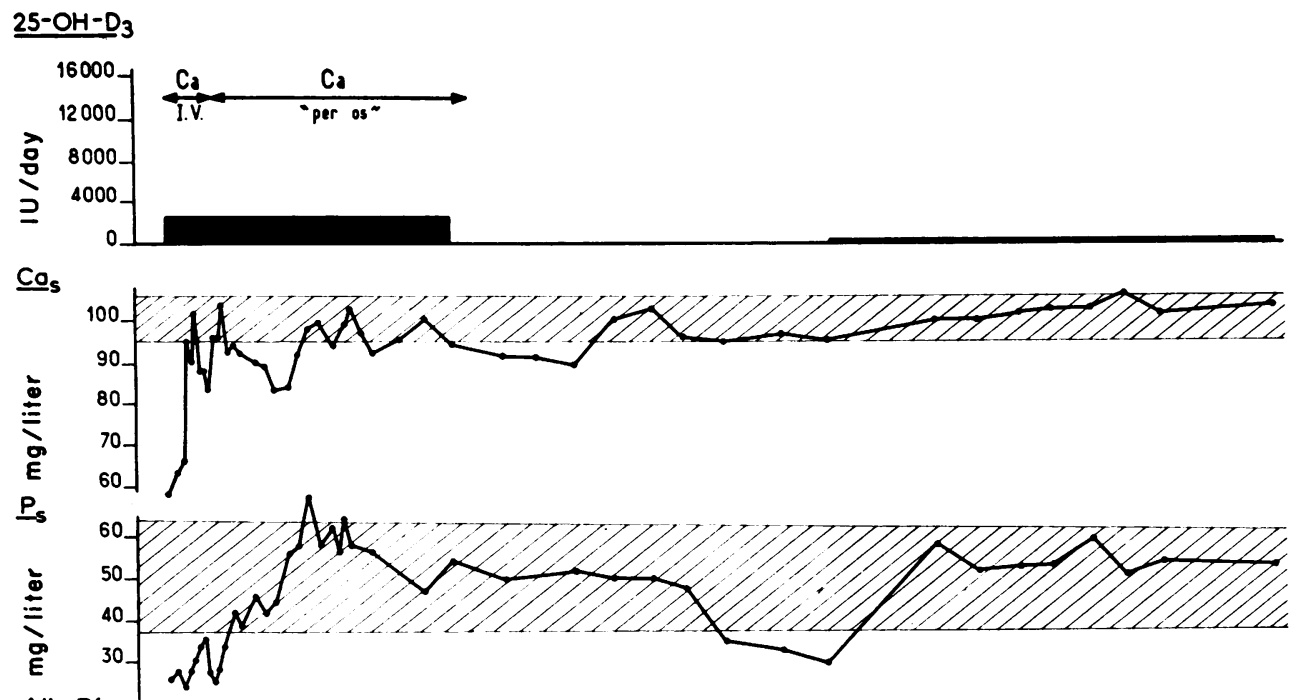

Alk. P'ose

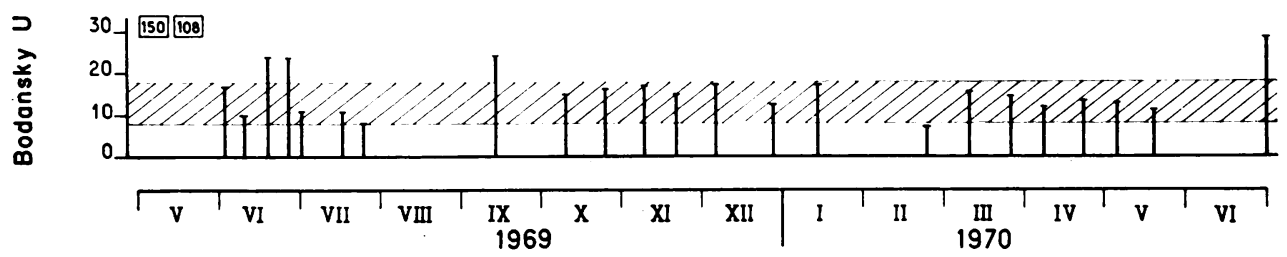

Figure 5 Effects of prolonged administration (2 months) of 2,640 IU/day of 25-HCC $\left(25-\mathrm{OH}-\mathrm{D}_{3}\right)$ in one patient with deficiency rickets. A relapse occurred 5 months after the end of $25-\mathrm{HCC}$ therapy as can be seen on the curve of serum phosphorous concentration $\left(\mathrm{P}_{\mathrm{s}}\right)$.

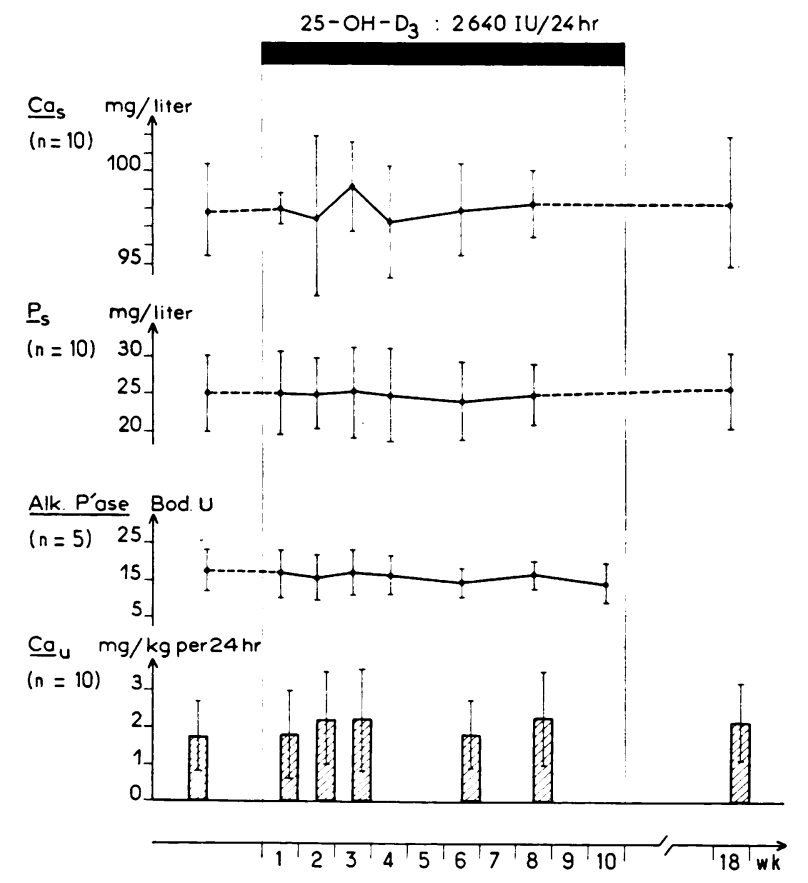

FIGURE 6 Prolonged administration of 25-hydroxycholecalciferol $\left(25-\mathrm{OH}-\mathrm{D}_{3}\right)$ in 10 cases of hereditary hypophosphatemic vitamin D-resistant rickets (VDRR). Mean \pm one SD (vertical bar) values are shown.

\section{DISCUSSION}

The definition of resistance to vitamin $\mathrm{D}$ is based on two criteria, first, unresponsiveness to small doses of vitamin $\mathrm{D}$ active in deficiency rickets, and second, relapse of rickets when treatment with high doses is stopped. At present, there is no evidence that $25-\mathrm{HCC}$ can be stored in the body. Therefore, the recurrence of

TABLE I

Effects of Increasing Doses of 25-HCC on the Serum Phophorus ( $\mathrm{mg} /$ liter) in 13 Cases of VDRR

(Numbers $I$ to XIII).

\begin{tabular}{cccccc}
\hline & \multicolumn{5}{c}{25 -HCC, IU/day } \\
\cline { 2 - 6 } Subjects & 6,000 & 12,000 & 18,000 & 24,000 & 30,000 \\
\hline & & \multicolumn{5}{c}{$m g /$ liter } \\
I-IV & $30-33.5$ & & & & \\
V & 18 & 32.5 & & & \\
VI-VIII & 26 & 28.5 & 28 & & \\
VIII & 21.5 & 21 & 26 & 20 & \\
IX & 25 & 25 & 27.5 & 26 & \\
X & 23 & 22 & 18 & 22 & \\
XI & 21.5 & 21.5 & 24 & 22 & \\
XII & 21 & 23 & 21 & 22 & 26 \\
XIII & 28 & 27 & 23 & 25 & 26 \\
\hline
\end{tabular}

Effect of 25-Hydroxycholecalciferol on Rickets 

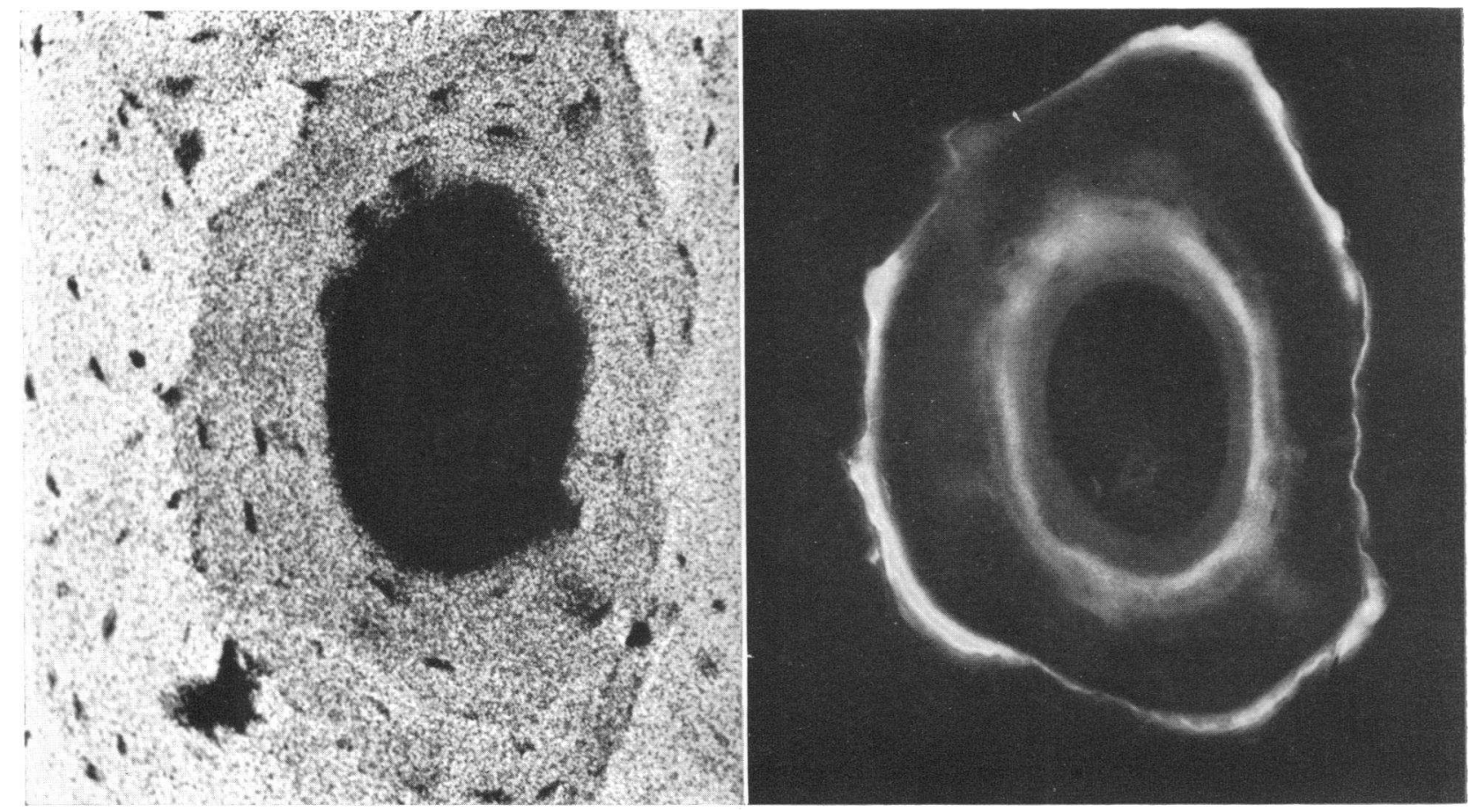

Figure 7 Microradiograph (on the left) and fluorescent image with UV light (on the right) of the same section of compact bone from the peroneus of patient B. C. (VDRR). Two tetracycline labelings show the borders of the tissue mineralized during 25-HCC therapy. This tissue shows lack of mineral around lacunae, canaliculi, and osteoid borders. $\times 600$.

rickets when $25-\mathrm{HCC}$ treatment is stopped cannot be a criterion for 25-HCC resistance until more information is available concerning the exact length of action of a given dose of 25 -HCC. Thus resistance to $25-\mathrm{HCC}$ has to be defined as an absence of response to doses that are known to be active in deficiency rickets.

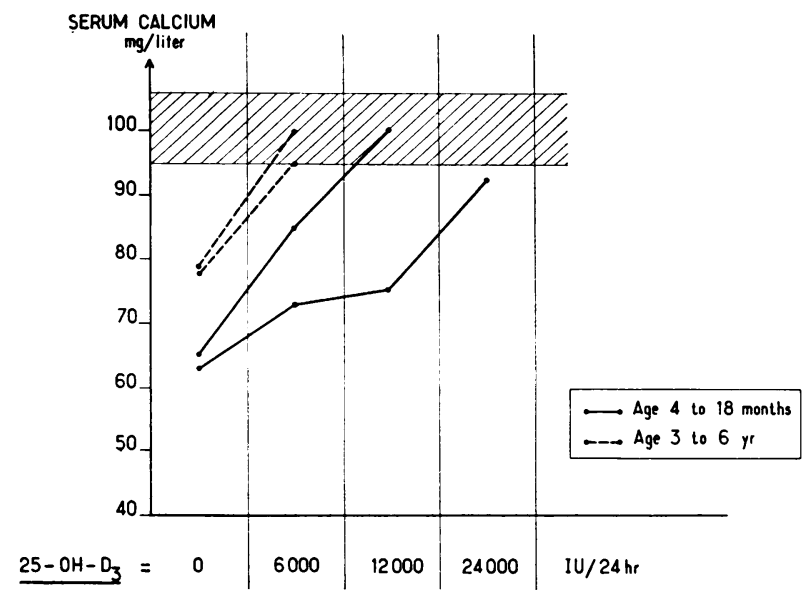

Figure 8 Effects of increasing doses patients with "pseudo-deficiency" rickets. Balsan and M. Garabedian
Our data show that $25-\mathrm{HCC}$ is highly active in human deficiency rickets. A single dose of 16,000 IU is followed in 8 days by normalization of serum phosphorous concentration. This biological response is quite similar to the response observed after administration of vitamin D. With $25-\mathrm{HCC}$, normalization of serum phosphorous

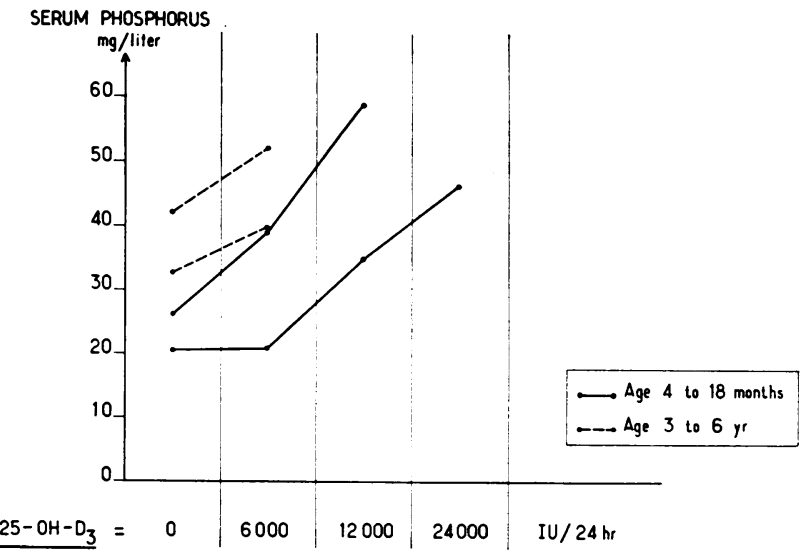

25-hydroxycholecalciferol (25-OH- $\left.\mathrm{D}_{3}\right)$ in four 
concentration is paralleled by an increase of serum calcium concentration, especially in the hypocalcemic type of deficiency rickets. This last observation is of special importance since it is known that the one danger of vitamin $\mathrm{D}$ treatment in cases of severe hypocalcemic deficiency rickets is the possibility of a sudden decrease in serum calcium concentration and the occurrence of tetany (32). This danger apparently does not exist with 25-HCC therapy. The observation of a rapid increase of serum calcium concentration that we made in one case, (basic serum calcium concentration 74 and $81 \mathrm{mg} / \mathrm{liter}$ ) has been confirmed in a group of hypocalcemic rickets treated with $25-\mathrm{HCC}^{3}$ These results suggest a direct effect of $25-\mathrm{HCC}$ on bone mobilization which supports the observation of Trummel, Raisz, Blunt, and DeLuca (12) with bone cultures.

The prolonged action of a single dose of $25-\mathrm{HCC}$ remains to be explained. Recent studies by Smith and Goodman (33) have shown that a polar metabolite of vitamin $\mathrm{D}$ with the properties of $25-\mathrm{HCC}$ has a halflife of $19.6 \pm 0.6$ days in man. A follow-up study in three cases of 25-HCC intoxication in patients with severe renal osteodystrophy that we have observed " has shown an effect of 25-HCC lasting from 1 to $3 \mathrm{wk}$ after the withdrawal of 25-HCC therapy. Thus the prolonged effects after the administration of a single dose of 25-HCC may be attributable to the persistance of 25-HCC and/or of some of the active dihydroxy metabolites in plasma and tissues.

In all cases of deficiency rickets studied, even in the most severe forms, the administration of 2,640 IU/day of $25-\mathrm{HCC}$ for 2 months promoted a rapid remineralization of the skeleton, a disappearance of symptoms, an amelioration of laboratory values, and "catch-up" growth. Furthermore a total dose of $3 \mathrm{mg}$ or $180,000 \mathrm{IU}$ of $25-\mathrm{HCC}$ was sufficient to protect these patients from any relapse for a period lasting 5 months. Yet a slight biological relapse occurred in two cases out of four, and was controlled with very small doses of 25-HCC, 400 IU/day. The reason why these two children had a relapse even though they were living in the same environmental conditions with the same type of diet remains to be explained. This suggests that the sensitivity of children to $25-\mathrm{HCC}$ is quite variable in a population, a fact which has also been noted with vitamin $D$ (34) and not yet explained satisfactorily. In any case, the observations in deficiency rickets of a persistent effect for 8 days after a single oral doses of 25-HCC and of an absence of relapse 5 months after the end of a treatment with a total dose of $3 \mathrm{mg}$ or $180,000 \mathrm{IU}$ of 25 $\mathrm{HCC}$ seems to indicate that prevention or treatment of

Frederich, A. Personal communication.

- Unpublished data. deficiency rickets does not necessarily require the continuous administration of $25-\mathrm{HCC}$.

The comparison of the effects of $25-\mathrm{HCC}$ in deficiency rickets with its effect in various types of resistant rickets showed striking differences. First, a single oral dose of 25-HCC had no effect on any of the parameters studied in any group of the D-resistant rickets investigated; hereditary hypophosphatemic D-resistant rickets, "pseudo-deficiency" rickets, or resistant rickets secondary to cystinosis or tyrosinosis. Secondly, prolonged administration of 2,640 IU/day was insufficient to correct the abnormally low levels of serum phosphorous in the children with hereditary hypophosphatemic D-resistant rickets. A similar observation was made by Earp et al. (25).

In the group of patients with VDRR it has been possible to increase significantly serum phosphorous concentration in 5 children out of 13 by using increasing doses of $25-\mathrm{HCC}$ from $6,000 \mathrm{IU}$ up to $30,000 \mathrm{IU} /$ day. No correlation was found between these differences in sensitivity toward 25-HCC and such factors as age, whether the disease is familial or sporadic, or the previous vitamin $D_{3}$ therapy. In regard to the last point, it should be noted that 12 of the 13 children who were studied received no vitamin $\mathrm{D}$ for 5 months before 25-HCC treatment under protocol C (increasing doses).

The 13 children with VDRR on increasing doses of 25-HCC were seen regularly in our clinic for periods of 6 months up to $2 \mathrm{yr}$. In all cases in which the serum phosphorous concentration persisted for months at concentrations equal to, or greater than, $30 \mathrm{mg} / \mathrm{liter}$, we observed a concomitant improvement of X-ray lesions; yet in none of these did an acceleration of growth occur. In contrast, all four children with "pseudo-deficiency" rickets had a complete normalization of their laboratory values, a healing of skeletal lesions, and a catch-up growth pattern. These differences of responses to 25-HCC therapy found between VDRR and "pseudodeficiency" rickets are similar to the differences of responses to vitamin D therapy already observed between the two types of resistant rickets.

From the analysis of our data and the definition of resistance to $25-\mathrm{HCC}$ given above, we may conclude that the patients studied with these different types of D-resistant rickets are all resistant to $25-\mathrm{HCC}$. Therefore, a defect in the conversion of vitamin $\mathrm{D}$ to its 25-hydroxy metabolite is not the metabolic defect in these patients. Our study does not however indicate what the defect might be in these different diseases. Recent studies (35-41) have shown that active metabolites of vitamin $\mathrm{D}$ other than 25-HCC exist. Three of these recently described metabolites have been isolated and identified: 21,25-dihydroxycholecalciferol (35), 25,26dihydroxycholecalciferol (36), and 1,25-dihydroxycho- 
lecalciferol $(40,41)$. The experimental studies suggest that the dihydroxy metabolites are organ specific and that $25-\mathrm{HCC}$ is the likely precursor for these dihydroxy metabolites. It is possible to speculate that a defect in the conversion of vitamin $D$ to one of the organ-specific dihydroxy metabolites might be the metabolic defect in one or in several of the different types of vitamin D-resistant rickets. Another hypothesis, as suggested by DeLuca et al. (22), is the nonresponse of the target $\operatorname{organ}(\mathrm{s})$ to the active metabolite $(\mathrm{s})$.

\section{ACKNOWLEDGMENTS}

We wish to express our grateful thanks to Dr. J. Guivarch, Chief of Medicine and Dr. M. Charlier, Head of the Biochemistry Laboratory, for having carefully supervised the clinical course of the tests performed at the Centre HelioMarin de Roscoff.

We wish to thank Miss A. Dartois, dietician, for the survey of the balance studies, Dr. G. Witmer for the histological and microradiographical studies, and Dr. Ch. Sachs for statistical analysis computer programming.

We wish to acknowledge the skillful technical assistance of Mrs. L. Creignou, and Misses M. Dromini, H. Guillozo, and V. Presle.

\section{REFERENCES}

1. DeLuca, H. F. 1969. Recent advances in the metabolism and function of vitamin D. Fed. Proc. 28: 1678.

2. Lund, J., and H. F. DeLuca. 1966. Biologically active metabolite of vitamin $\mathrm{D}_{3}$ from bone, liver and blood serum. J. Lipid Res. 7: 739.

3. Blunt, J. W., H. F. DeLuca, and H. K. Schoes. 1968. 25-Hydroxycholecalciferol. A biologically active metabolite of vitamin $\mathrm{D}_{3}$. Biochemistry. 7: 3317.

4. Suda, T., H. F. DeLuca, H. K. Schnoes, and J. W. Blunt. 1969. The isolation and identification of 25hydroxyergocalciferol. Biochemistry. 8: 3515.

5. Suda, T., H. F. DeLuca, H. K. Schnoes, and R. B. Hallick. 1970. 25-Hydroxydihydrotachysterol ${ }_{8}$ : synthesis and biological activity. Fed. Proc. 29: 367. (Abstr.)

6. Stohs, S. J., and H. F. DeLuca. 1967. Subcellular location of vitamin D and its metabolites in intestinal mucosa after a 10 IU dose. Biochemistry. 6: 3338.

7. Blunt, J. W., Y. Tanaka, and H. F. DeLuca. 1968. The biological activity of 25-hydroxycholecalciferol, a metabolite of vitamin $\mathrm{D}_{3}$. Proc. Nat. Acad. Sci. U. S. A. 61: 717.

8. Horsting, M., and H. F. DeLuca. 1969. "In vitro" production of 25-Hydroxycholecalciferol. Biochem. Biophys. Res. Commun. 36: 251.

9. Martin, D. L., M. J. Melancon, Jr., and H. F. DeLuca. 1969. Vitamin D stimulated, calcium dependent adenosine triphosphatase from brush borders of rat small intestine. Biochem. Biophys. Res. Commun. 35: 819.

10. Olson, E. B., and H. F. DeLuca. 1969. 25-Hydroxycholecalciferol: a direct effect on calcium transport. Science (Washington). 165: 405.

11. Ponchon, G., and H. F. DeLuca. 1969. The role of the liver in the metabolism of vitamin D. J. Clin. In vest. 48: 1273.
12. Trummel, C. L., L. G. Raisz, J. W. Blunt, and H. F. DeLuca. 1969. 25-Hydroxycholecalciferol: stimulation of bone resorption in tissue culture. Science (Washington). 163: 1450

13. Chen, T. C., J. C. Weber, and H. F. DeLuca. 1970. On the subcellular location of vitamin $\mathrm{D}$ metabolites in intestine. J. Biol. Chem. 245 : 3776.

14. Cousins, R. J., H. F. DeLuca, T. Suda, T. Chen, and Y. Tanaka. 1970. Metabolism and subcellular location of 25-hydroxycholecalciferol in intestinal mucosa. Biochemistry. 9: 1453.

15. Horsting, M., and H. F. DeLuca. 1970. Feed-back control of 25-hydroxycholecalciferol production. Fed. Proc. 29: 542. (Abstr.)

16. Suda, T., H. F. DeLuca, and Y. Tanaka. 1970. Biological activity of 25-Hydroxycholecalciferol. J. Nutr. 100: 1049.

17. Balsan, S., J. Guivarch, Ch. Sachs, and M. Garabedian. 1970. 25-Hydroxycholecalciferol. Effet d'une dose unique chez l'enfant normal. Rev. Europ. Etudes Clin. Biol. 15: 515.

18. Pak, C. Y. C., H. F. DeLuca, J. M. Chavez de los Rios, and T. Suda. 1969. Treatment of vitamin D resistance with 25-hydroxycholecalciferol. Clin. Res. 17: 291. (Abstr.)

19. Balsan, S. 1970. 25-Hydroxycholecalciferol: effects in idiopathic vitamin D-resistant rickets. Calcified Tissue Res. 4(Suppl.) : 45 .

20. Hioco, D., L. Miravet, and Ph. Bordier. 1970. Activité biologique du 25-hydroxycholécalciferol dans les ostéomalacies vitamino-résistantes. Calcified Tissue Res. 4 (Suppl.) : 47 .

21. Seely, J. R., H. Coussons, J. D. Smith, and H. F. DeLuca. 1970. Effective treatment of hypophosphatemic vitamin D-resistant rickets (VDRR) with 25-hydroxycholecalciferol (25-HCC). Pediat. Res. 4: 451. (Abstr.)

22. DeLuca, H. F., J. Lund, A. Rosenbloom, and C. C. Lobeck. 1967. Metabolism of tritiated vitamin $\mathrm{D}_{3}$ in familial vitamin D-resistant rickets with hypophosphatemia. J. Pediat. 70: 828.

23. Avioli, L. V., S. Birge, S. W. Lee, and E. Slatopolsky. 1968. The metabolic fate of vitamin $\mathrm{D}_{3}{ }^{-} \mathrm{H}$ in chronic renal failure. J. Clin. Invest. 47: 2239.

24. Avioli, L. V., T. F. Williams, J. Lund, and H. F. DeLuca. 1967. Metabolism of vitamin $\mathrm{D}_{\mathbf{p}^{-}}{ }^{3} \mathrm{H}$ in vitamin D-resistant rickets and familial hypophosphatemia. $J$. Clin. Invest. 46: 1907.

25. Earp, H. S., R. L. Ney, H. J. Gitelman, R. Richeman, and H. F. DeLuca. 1970. Effects of 25-hydroxycholecalciferol in patients with familial hypophosphatemia and vitamin D-resistant rickets. N. Engl. J. Med. 283: 627.

26. Prader, A., R. Illig, and E. Heierli. 1961. Eine besondere Form der primären vitamin $\mathrm{D}$ resistenter Rachitis mit Hypocalcämie und autosomal dominanten Erbgang: die hereditäre Pseudo-mangelrachitis. Helv. Paediat. Acta. 16: 452.

27. Blunt, J. W., and H. F. DeLuca. 1969. The synthesis of 25-hydroxycholecalciferol. A biologically active metabolite of vitamin $D_{3}$. Biochemistry. 8: 671 .

28. Wiene, R. J., and E. R. Van Raepenbush. 1962. Automatic determination of calcium in blood and urine using corinth ca. Clin. Chim. Acta. 7: 889.

29. Antener, I., L. Vuataz, A. Bruschi, and M. Kaeser. 1966. Determination of citric acid in urine and in serum. Z. Klin. Chem. 6: 296. 
30. Witmer, G., and S. Balsan. 1968. Biopsie osseuse dans quatre cas de rachitisme vitamino-résistant idiopathique. Pathol. Biol. 16: 421.

31. Schwartz, D. 1963. Méthodes Statistiques à l'usage des Médecins et Biologistes. Flammarion et Cie, Paris, 3d edition. 157 and 247.

32. Fourman, P., and P. Royer. 1968. Calcium Metabolism and the Bone. Blackwell Scientific Publications, Ltd., Oxford. 2nd edition. 274.

33. Smith, J. E., and D. S. Goodman. 1971. The turnover and transport of vitamin $\mathrm{D}$ and of a polar metabolite with the properties of 25-Hydroxycholecalciferol in human plasma. J. Clin. Invest. 50: 2159.

34. Seeling, M. S. 1969. Vitamin D. and cardiovascular, renal, and brain damage in infancy and childhood. Ann. N. Y. Acad. Sci. 147: 539.

35. Suda, T., H. F. DeLuca, H. K. Schnoes, G. Ponchon, Y. Tanaka, and M. F. Holick. 1970. 21,25-Dihydroxycholecalciferol. A metabolite of vitamin $\mathrm{D}_{3}$ preferentially active on bone. Biochemistry. 9: 2917.
36. Suda, T., H. F. DeLuca, H. K. Schnoes, Y. Tanaka, and M. F. Holick. 1970. 25,26-Dihydroxycholecalciferol. A metabolite of vitamin $\mathrm{D}_{3}$ with intestinal calcium transport activity. Biochemistry. 9: 4776.

37. Haussler, M. R., E. T. Littledike, D. W. Boyce, and H. Rasmussen. 1971. A rapidly acting metabolite of vitamin D. Proc. Nat. Acad. Sci. U.S. A. 68: 177.

38. Myrtle, M. F., and A. W. Norman. 1971. Vitamin D: a cholecalciferol metabolite highly active in promoting intestinal calcium transport. Science (Washington). $171: 79$.

39. Kodicek, E., D. E. M. Lawson, and P. W. Wilson. 1970. Biological activity of a polar metabolite of vitamin $\mathrm{D}_{3}$. Nature (London). 228: 763.

40. Fraser, D. R., and E. Kodicek. 1970. Unique biosynthesis by kidney of biologically active vitamin D metabolite. Nature (London). 228: 764.

41. Holick, M. F., H. K. Schnoes, and H. F. DeLuca. 1971. Identification of a form of vitamin $\mathrm{D}_{3}$ metabolically active in the intestine. Proc. Nat. Acad. Sci. U. S. A. 68: 803. 